\title{
CARACTERIZAÇÃO DA COMPOSIÇÃO gUÍMICA E DO RENDIMENTO DOS RESÍDUOS INDUSTRIAIS DO LIMÃO TAHITI (Citrus latifolia Tanaka) ${ }^{1}$
}

\author{
Luciana Maria Vieira Lopes MENDONÇA ${ }^{2 *}$, Alzira da CONCEIÇÃO ${ }^{3}$, Juliana PIEDADE ${ }^{4}$, \\ Vânia Déa de CARVALHO ${ }^{5}$, Vanessa Cristina de Almeida THEODORO ${ }^{6}$
}

\begin{abstract}
RESUMO
A indústria de sucos utiliza apenas de $40 \%$ a $50 \%$ dos frutos, sendo o restante considerado resíduo industrial. Estes resíduos apresentam-se ricos em alguns componentes como pectina, vitamina $\mathrm{C}$ e fibras dietárias que o tornam matéria-prima para a indústria alimentícia, farmacêutica e de rações. Visando o aproveitamento dos resíduos industriais do limão Tahiti para tais fins, caracterizouse a composição centesimal, os teores de fibras, de pectina e de vitamina C presentes nas frações flavedo, albedo e bagaço do fruto. A partir da avaliação dos dados pelo teste de Scott Knott 5\% de probabilidade, observou-se que os teores de cinzas, pectina, proteína, vitamina $\mathrm{C}$ e fibra bruta foram diferentes no flavedo, albedo e bagaço. O resíduo industrial do limão Tahiti tem um grande potencial para uso em formulação de rações para animais, dada a sua composição química, assim como poderá ser usado para a extração de fibras, pectina, vitamina $\mathrm{C}$ e óleos.

Palavras-chave: citrus, composição química, fibras dietárias, aproveitamento.
\end{abstract}

\section{SUMMARY}

CHEMICAL COMPOSITION AND TAHITI LIME INDUSTRIAL RESIDUES OUTPUT CHARACTERIZATION.The juice industry makes use of only 40 to $50 \%$ of the fruit and its remainder is considered industrial residue. This residue is very rich in some of its compounds such as pectin, ascorbic acid and dietary fibers making it into raw material for the food industry, pharmaceutics and animal food. With the purpose of using the industrial residue of Tahiti lime for such purposes, the centesimal composition, fiber contents, pectin and vitamin $\mathrm{C}$ contained in flavedo fractions, albedo and fruit pulp were characterized. From the evaluation for the Scott Knott's test to $5 \%$ of probability, it was observed that the ash content, pectin, protein, vitamin $\mathrm{C}$ and rude fiber were different for flavedo, albedo and pulp. Tahiti lime industrial residue has a great potential for animal food formulation, considering its chemical composition, as well as the fact that it can be used for fiber extraction, pectin, vitamin $\mathrm{C}$ and oils.

Keywords: citrus, chemical composition, dietary fibers, use.

\section{1 - INTRODUÇÃO}

O limão Tahiti é um fruto de origem tropical, de exploração econômica relativamente recente. No contexto mundial, os principais produtores são o México, EUA (Flórida), Egito, Índia, Peru e Brasil. É uma das espécies de citros de maior precocidade, apresentando, já a partir do terceiro ano, uma produção significativa [5]. O Brasil se destaca como o segundo maior produtor de frutos cítricos e o maior exportador de sucos cítricos, tendo o limão Tahiti como um dos seus frutos de maior relevância comercial. A produção brasileira de limão no período de 1992 a 1999 passou de pouco mais de 600 mil toneladas para mais de 700 mil toneladas em 46.554 ha, com incremento de 4,5 mil ha no período. O Es-

\footnotetext{
${ }^{1}$ Recebido para publicação em 22/03/2006. Aceito para publicação em 20/10/2006 (001699)

${ }^{2}$ Laboratório de Bromatologia e Água,

Escola Agrotécnica Federal de Muzambinho, Muzambinho (MG), Brasil, E-mail:luciana@eafmuz.gov.br

${ }^{3}$ Pólo de Qualidade em Pós-Colheita do Café,

Universidade Federal de Lavras (UFLA), C. P. 37, CEP 37200-000, Lavras (MG), Brasil

${ }^{4}$ Escola Superior de Agricultura "Luiz de Queiroz" (ESALQ/USP),

Piracicaba (SP), Brasil

${ }^{5}$ Departamento de Ciência dos Alimentos (DCA),

Universidade Federal de Lavras (UFLA), Lavras (MG), Brasil

${ }^{6}$ Departmento de Agricultura (DAG),

Universidade Federal de Lavras (UFLA), Lavras (MG), Brasil

* A quem a correspondência deve ser enviada
}

tado de São Paulo é o primeiro produtor deste fruto, tendo participação em $81,3 \%$ da produção, seguido pelo Rio de Janeiro e Bahia, com 3,9\% e 2,7\%, respectivamente [18].

O volume do material descartado pelas indústrias na obtenção do suco é, em média, de $45 \%$ dos frutos. Este resíduo apresenta grande potencial para ser usado como matéria-prima de excelente qualidade para as indústrias farmacêutica, alimentícia e de rações [23].

O peso médio do fruto do limão Tahiti é de $170 \mathrm{~g}$, sendo a casca geralmente fina, com superfície lisa e cor amarelo pálido na etapa de maturação. É composta de duas frações distintas: o "flavedo" ou epicarpo e o "albedo" ou mesocarpo, facilmente separáveis da polpa, que corresponde à fração comestível do fruto. No "flavedo" encontram-se substâncias químicas como os carotenóides, vitaminas e óleo essencial. O "albedo" que corresponde à porção esponjosa, branca e aderente à casca, é rico em hemicelulose, celulose, lignina, glicídeos solúveis, substâncias pécticas e compostos fenólicos. A polpa das frutas cítricas apresenta aproximadamente 10 segmentos com eixo (vesículas que contém suco ou "bagaço"). As paredes das vesículas de suco são compostas por celulose, hemicelulose, substâncias pécticas, açúcares, flavonóides, vitaminas, sais minerais. O suco das vesículas representa cerca de $50 \%$ do peso do fruto, apresentando teor de ácido ascórbico entre 20 e $40 \mathrm{mg} / 100 \mathrm{~mL}$ [5]. Os principais constituintes solúveis são glicídeos, ácidos orgânicos, 
principalmente o cítrico, vitaminas, sais minerais e bem como pequenas concentrações de compostos nitrogenados e substâncias pécticas [19].

Nos EUA, a partir de 1911, iniciaram-se os estudos para o uso de frutas frescas descartadas ou fora de padrão para o comércio. Estes estudos comprovaram que os subprodutos cítricos apresentam alta palatabilidade, quando utilizados para a alimentação de ruminantes [8].

Em trabalhos realizados com bovinos confinados, foi observado que as dietas poderiam conter até 30\% de polpa cítrica peletizada, substituindo o milho desintegrado, obtendo excelentes resultados e promovendo também uma melhoria na conversão alimentar [22].

O uso dos resíduos industriais de frutos cítricos na dieta animal destaca a importância da fibra na manutenção da motilidade ruminal e no estímulo à ruminação, no entanto, esta fibra deve estar na forma efetiva. Considera-se que $70 \%$ da F. D. A. (fibra detergente ácida) são efetivos, contudo, outros autores ajustam o valor de F. D. N. (fibra detergente neutra) efetivo para $12 \%$ da matéria seca total [16].

A ingestão de fibras alimentares na alimentação humana tem sido correlacionada com a prevenção de muitas doenças. Fibra da dieta ou fibra alimentar é um termo geral que se refere a todos os componentes da parede celular incluindo: celulose, hemicelulose, lignina, pectinas, mucilagens e gomas [15].

As paredes celulares de plantas são as maiores fontes destas fibras. Estes compostos influenciam a textura e a palatabilidade da dieta, promovendo a saciedade e a redução na ingestão de calorias por que retardam o esvaziamento gástrico e promovem uma lenta absorção de glicose [15]. Estas fibras modulam também a absorção de nutrientes no intestino delgado, que podem ser fermentados no intestino grosso pelas bactérias anaeróbicas, aumentando o volume do bolo fecal e reduzindo o tempo de trânsito do mesmo, o que promove a remoção de compostos potencialmente nocivos [7].

Um exemplo de um fruto cujos resíduos são utilizados para a obtenção de outros produtos é o do fruto do maracujazeiro. Na fabricação de sucos, os resíduos são compostos principalmente por casca e sementes, que podem ser utilizados na alimentação animal e na produção de óleo e pectina. A casca do fruto pode ser utilizada na fabricação de compotas e na fabricação de farinhas ricas em fibras dietéticas. As sementes podem ser utilizadas na produção de óleos essenciais para a indústria alimentícia e de perfumes e, ainda, as folhas, as raízes e as sementes têm propriedades farmacológicas [14].

A composição química dos frutos cítricos sofrem variações em função do clima, dos tratos culturais, do tipo de solo, das cultivares utilizadas e ainda entre as partes de um mesmo fruto [4].

Conhecendo-se o potencial de aproveitamento do resíduo industrial de frutos cítricos e pela falta de trabalhos que caracterizem a composição química destes resíduos, a pesquisa teve por objetivo caracterizar os componentes químicos do flavedo, albedo e bagaço do limão Tahiti (Citrus latifolia Tanaka).

\section{2 - MATERIAL E MÉTODOS}

\section{1 - Caracterização do experimento}

No município de Ijaci, região sul de Minas Gerais, foram coletados frutos de 10 árvores na altura média da copa, nos quatro quadrantes, totalizando 200 frutos. Estes frutos foram misturados e selecionaram-se ao acaso 160 unidades, que constituíram 8 parcelas com 20 frutos. O experimento constou de um Delineamento Inteiramente Casualizado com 3 tratamentos (flavedo, albedo e bagaço) e oito repetições.

\section{2 - Preparo das amostras}

Os frutos foram lavados em água corrente, secos em temperatura ambiente e pesados. Em seguida, o limão foi descascado retirando-se somente o flavedo (epicarpo). O fruto foi partido ao meio, para extrair o suco, separando-se manualmente o albedo (mesocarpo) das vesículas que contém o suco, comumente denominadas de bagaço (endocarpo). Os produtos obtidos, tratamentos flavedo, albedo e bagaço foram pesados e triturados em processador de alimentos marca Wallita Master.

Reservaram-se aproximadamente $50 \mathrm{~g}$ de cada parcela para análise dos teores de Vitamina $\mathrm{C}$, pectina e umidade, e o restante foi colocado para secar em estufa a $65{ }^{\circ} \mathrm{C}$ para serem realizadas as análises propostas, na matéria seca.

\section{3 - Metodologia analítica}

Todas as análises foram realizadas em triplicata.

\subsection{1 - Umidade}

O teor de umidade foi determinado em estufa regulada à temperatura de $65{ }^{\circ} \mathrm{C}$, até peso constante.

\subsection{2 - Proteína}

Foi determinado o teor de nitrogênio utilizando-se a técnica do micro-Kjeldahl [2], e o teor de proteína foi obtido multiplicando-se o teor de nitrogênio pelo fator de conversão 6,25.

\subsection{3 - Extrato etéreo}

Foi obtido por extração contínua, em aparelho do tipo Soxhlet, usando-se, como solvente extrator, o éter etílico [2].

\subsection{4 - Cinzas}

Foram determinadas pelo método gravimétrico usando-se uma mufla regulada na temperatura de $550{ }^{\circ} \mathrm{C}$. São constituídas pelos minerais da amostra analisada [2]. 


\subsection{5 - Fibra bruta}

Foi determinada por hidrólise ácida, usando-se os ácidos acético, tricloroacético e nítrico, segundo o procedimento de VAN DE KAMER \& VAN GINKEl [20].

\subsection{6 - Fibra detergente ácido}

Foi determinada segundo a metodologia de Van Soest por hidrólise com solução detergente ácida durante $1 \mathrm{~h}$, usando-se o cadinho de vidro, para filtragem do material hidrolisado, seguida de lavagem com acetona [21].

\subsection{7 - Pectina}

Extraída conforme a técnica de McCREADY \& McCOMB [13] e a determinação foi feita segundo a técnica de BITTER \& MUIR [3].

\subsection{8 - Vitamina C}

Determinada pelo método colorimétrico de Roe e Kuether, citados por STROHECKER \& HENNING [17].

\section{4 - Análise estatística}

O delineamento utilizado foi o inteiramente casualizado (DIC) com 8 repetições e 3 partes do fruto (flavedo, albedo e bagaço), tendo sido consideradas 8 variáveis estudadas. O suco foi considerado para a avaliação do rendimento percentual do fruto, juntamente com as outras três partes avaliadas.

Os dados foram avaliados pelo software Sisvar [6] e submetidos ao teste de Scott-Knott ao nível de 5\% de significância.

\section{3 - RESULTADOS E DISCUSSÃO}

O processamento do limão Tahiti para obtenção do suco produz uma quantidade expressiva de resíduos que equivalem, em média, a 49,8\% do peso do fruto (Figura 1). O suco corresponde aos demais 50,1\%. Este resultado demonstra a grande perda de material que ocorre durante o processamento industrial do limão Tahiti. Deste volume de material descartado, observa-se ainda que o albedo, juntamente com o bagaço, representa a segunda maior porção, em peso fresco.

Os resultados obtidos e apresentados nas Tabelas 1, 2 e 3 permitem constatar diferenças estatísticas significativas entre as três frações do fruto (flavedo, albedo e bagaço), para todos os constituintes analisados.

Os dados da Tabela 1 mostram que houve diferenças significativas para os teores de umidade, cinzas (minerais) e extrato etéreo entre as diferentes frações do limão Tahiti.

A fração flavedo, a mais externa do fruto, destacou-se com o maior teor de cinzas. VILAS BOAS et al. [23] citam que as folhas, as cascas e as sementes apresentam os maiores

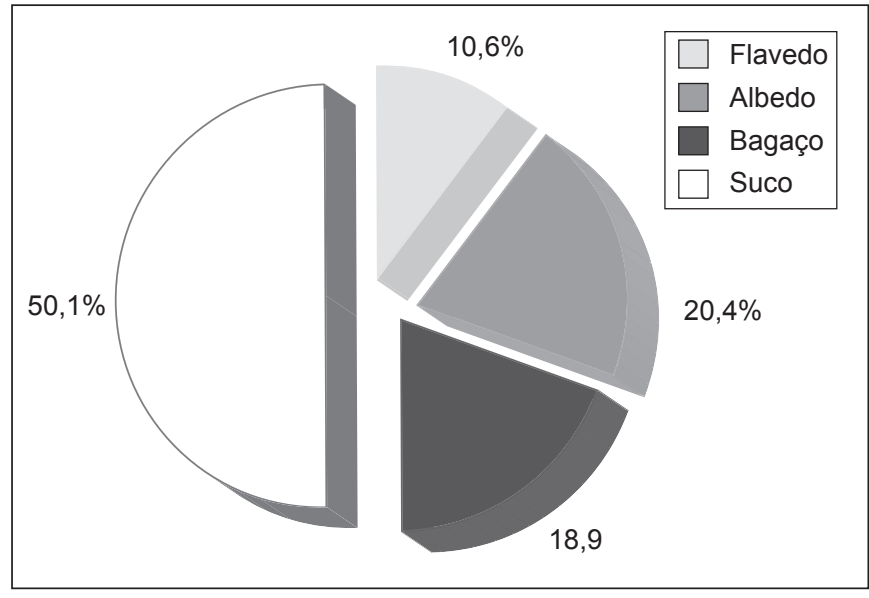

FIGURA 1 - Rendimento das frações albedo, bagaço, flavedo e suco do limão Tahiti (Citrus latifolia Tanaka).

TABELA 1 - Teores (\% matéria seca) de umidade, extrato etéreo e cinzas (minerais) das frações flavedo, albedo e bagaço do limão Tahiti (Citrus latifolia Tahaka).

\begin{tabular}{cccccccccc}
\hline Fração & \multicolumn{3}{c}{ Umidade } & \multicolumn{4}{c}{ Extrato etéreo } & \multicolumn{3}{c}{ Cinzas } \\
\hline Flavedo & 71,30 & b & 2,74 & a & & 5,15 & a & \\
Albedo & 69,43 & & b & 1,27 & & b & 2,45 & & C \\
Bagaço & 81,36 & a & & 3,21 & a & & 3,98 & b \\
C.V. (\%) & 3,76 & & & 24,81 & & & 11,93 & & \\
\hline *médias seguidas pela mesma letra não diferem entre si, pelo teste de Scott-Knott, em
\end{tabular}

*médias seguidas pela mesma letra não diferem entre si, pelo teste de Scott-Knott, em nível de $5 \%$ de probabilidade.

teores de substâncias nutricionalmente importantes, como as fibras e os minerais.

$\mathrm{O}$ alto teor de umidade observado no bagaço justificase pelo fato dessa parte do fruto também corresponder às vesículas de suco. Não foram observadas diferenças entre as frações albedo e bagaço, para esta variável.

O flavedo e o bagaço não diferiram entre si quanto aos teores de extrato etéreo, e apresentaram maiores valores em relação ao albedo.

As indústrias farmacêutica e alimentícia utilizam os óleos essenciais retirados das cascas das frutas cítricas. O óleo essencial, que é extraído da casca do fruto, apresenta um rendimento de $1 \mathrm{~kg}$ de óleo para cada 2.500 limóes. Tratase de um líquido oleoso de cor amarelo-esverdeada pálida que apresenta o inconfundível cheiro de limões frescos, ou seja, é a mais pura essência da casca do limão. É constituído de uma mistura natural de diversos aldeídos, entre eles o citronelal, o citral e outros [10], sendo que o componente químico que predomina é um aldeído chamado d-limoneno. Com base nestes resultados, poderá ser o bagaço, também uma excelente matéria-prima potencial para extração de óleos, os quais deverão ainda ser mais bem estudados e caracterizados.

Quanto à fibra bruta e à fibra detergente ácido (Tabela 2), as frações flavedo e albedo apresentaram os maiores valores, destacando-se a importância deste material descartado 
como fonte potencial de fibra para a alimentação humana e animal. Estas fibras poderão ser extraídas de ambas as partes do fruto, para comporem as dietas ou serem usadas na elaboração de produtos, cuja função é promover a saciedade e a redução na ingestão de calorias de acordo com NEVES (1997) [15].

Os dados obtidos para pectina, proteína e vitamina $\mathrm{C}$ apresentados na Tabela 3 mostram que houve diferenças significativas entre as três frações do limão Tahiti (flavedo, albedo e bagaço).

TABELA 2 - Teores médios (\% matéria seca) de fibra bruta e fibra detergente ácido das frações flavedo, albedo e bagaço do limão Tahiti (Citrus latifolia Tahaka).

\begin{tabular}{|c|c|c|c|c|c|}
\hline Fração & \multicolumn{2}{|c|}{ Fibra Bruta } & & \multicolumn{2}{|c|}{$\begin{array}{c}\text { Fibra Detergente } \\
\text { Ácido }\end{array}$} \\
\hline Flavedo & 13,99 & b & & 24,67 & $a$ \\
\hline Albedo & 15,24 & a & & 24,71 & a \\
\hline Bagaço & 9,39 & & c & 17,28 & b \\
\hline C.V. (\%) & 8,64 & & & 5,60 & \\
\hline
\end{tabular}

*médias seguidas pela mesma letra não diferem entre si, pelo teste de Scott-Knott, em nível de $5 \%$ de probabilidade.

TABELA 3 - Teores médios de pectina e proteína (\% na matéria seca) e de vitamina $\mathrm{C}$ ( $\mathrm{mg} / 100 \mathrm{~g}$ de peso fresco), das frações flavedo, albedo e bagaço do limão Tahiti (Citrus latifolia Tanaka).

\begin{tabular}{|c|c|c|c|c|c|c|c|c|c|c|}
\hline \multirow{2}{*}{$\begin{array}{l}\text { Fração } \\
\text { Flavedo }\end{array}$} & \multicolumn{3}{|c|}{ Pectina } & \multicolumn{4}{|c|}{ Proteína (1) } & \multicolumn{3}{|c|}{$\begin{array}{l}\text { Vitamina C } \\
\text { (mg/100 g de } \\
\text { peso fresco) }\end{array}$} \\
\hline & 12,85 & & c & 5,80 & & b & & 242,37 & $a$ & \\
\hline Albedo & 22,85 & $a$ & & 3,67 & & & c & 108,15 & b & \\
\hline Bagaço & 18,92 & & b & 6,77 & a & & & 56,07 & & c \\
\hline C.V. (\%) & 5,32 & & & 6,36 & & & & 18,26 & & \\
\hline
\end{tabular}

(1) \% N x 6,25; e *médias seguidas pela mesma letra não diferem entre si, pelo teste de Tukey, em nível de $5 \%$ de probabilidade.

O teor de pectina do albedo foi superior aos teores encontrados no flavedo e no bagaço do mesmo fruto. CARVALHO et al. [4], avaliando os resíduos industriais de seis frutos cítricos, (Tangor Murcott, Tangerina Ponkan, Limão Galego, Limão Siciliano e Laranja Hamlim), observaram teores de pectina também maiores no albedo e nas vesículas da Laranja Hamlim, no entanto, estes valores foram inferiores aos determinados no albedo do limão Tahiti. Estas variações podem estar associadas às diferenças morfofisiológicas existentes em frutos do mesmo gênero.

A turbidez dos sucos cítricos, uma característica exigida pelos consumidores, é uma mistura de partículas em suspensão contendo lipídios, proteínas, pectina, celulose e hemicelulose, e que resulta da ruptura das células do fruto durante a extração [10]. No entanto, a pectina é normalmente referida como sendo o componente que naturalmente estabiliza a turbidez dos sucos cítricos, devido à sua ação emulsificante [1]. Levando-se em conta tais considerações e devido aos altos teores de pectina totais encontrados nos resíduos do limão Tahiti, considera-se importante a realização de um estudo mais detalhado, para avaliar a viabilidade de extração e uso desta pectina pela indústria de sucos.

Com relação aos teores de proteína, houve variações entre as frações estudadas, sendo os maiores teores encon- trados, em ordem decrescente, no bagaço, flavedo e albedo. Os teores de proteína somados aos outros constituintes determinados caracterizam os resíduos do limão Tahiti, como uma boa opção de alimento a ser acrescentado na formulação de pelets, contribuindo para o aumento do valor nutritivo destas rações oferecidas a animais, principalmente pelo do teor de fibras que apresentam.

Os teores de vitamina $\mathrm{C}$ foram diferentes para as três partes do fruto, (Tabela 3). O flavedo foi destacadamente, a fração com o maior teor de vitamina $\mathrm{C}$, seguido do albedo e bagaço. O maior teor no flavedo pode ser atribuído à exposição aos raios solares, pois a insolação é uma das principais causas do aumento dos teores de vitamina $\mathrm{C}$ em frutos e hortaliças [9]. Isso pode explicar a diminuição nos teores da vitamina $\mathrm{C}$ a partir da fração exterior (flavedo) para as interiores (albedo, bagaço e suco, respectivamente), resultando num teor médio de vitamina $\mathrm{C}$ para o suco do limão de 80 mg/100 g (em base seca) [12].

CARVALHO et al. [4] também encontraram quantidades maiores de vitamina $\mathrm{C}$ na casca (flavedo), em comparação ao albedo, apresentando uma diferença entre ambas as frações de $41,50 \mathrm{mg} / 100 \mathrm{~g}$ para o Limão Siciliano e de 160,25 mg/100 g para a Tangerina Ponkan.

Considerando-se o grande volume de resíduos gerados no processamento do Limão Tahiti, e o valor nutricional que apresentam, torna-se interessante o uso destes resíduos para extração de pectina, fibras e óleos, assim como o seu emprego para produção de rações para animais.

\section{4 - CONCLUSÕES}

Considerando as condições experimentais em que o trabalho foi realizado, concluiu-se que:

a) Os teores de cinzas, pectina, proteína, vitamina $\mathrm{C}$ e fibra bruta foram diferentes no flavedo, albedo e bagaço.

b) $\mathrm{Na}$ fração flavedo foram determinados os maiores teores de cinzas e vitamina $\mathrm{C}$, enquanto o albedo destacou-se com os maiores teores de pectina e de fibra bruta. No bagaço, os teores de umidade e de proteína foram os maiores.

c) O flavedo e o bagaço apresentaram em média o mesmo teor de extrato étereo e o flavedo e o albedo, os maiores teores de fibra detergente ácido.

d) O resíduo industrial do limão Tahiti tem um grande potencial para uso em formulação de rações para animais, dada a sua composição química, assim como poderá ser usado para a extração de fibras, pectina, vitamina C e óleos.

\section{5 - REFERÊNCIAS BIBLIOGRÁFICAS}

[1] AMSTALDEN, L. C. Estudo sobre a ação de pectinesterase em suco de laranja. Campinas, 1992. 188 p. Tese (Mestre em Tecnologia de Alimentos) - Faculdade de Engenharia de Alimentos, Universidade Estadual de Campinas.

[2] ASSOCIATION OF OFFICIAL AGRICULTURAL CHEMISTS. Official Methods of analysis of the association 
of the agricultural chemists. $15^{\circ} \mathrm{Ed}$. Washington, 1990 $2 \mathrm{v}$.

[3] BITTER, V.; MUIR, H. M. A modified uronic acid carbazole reaction. Analytical Biochemistry, New York, v. 4, p. 330-334, 1962.

[4] CARVAlHO, V. D. de; COSTA, L. C. G.; PÁDUA, T. de; CHALFUN, S. M.; CARVALHO, J. G. de. Caracterização dos componentes químicos de subprojetos das indústrias de frutos. In: EMPRESA DE PESQUISA AGROPECUÁRIA DE MINAS GERAIS. Projeto fruticultura. Belo Horizonte, 1978. p. 276-79. (Relatório Técnico 74/77).

[5] COELHO, I. da S. Lima ácida 'Tahiti' para exportação: aspectos técnicos da produção. Ministério da Agricultura, do Abastecimento e da Reforma Agrária, Secretaria de Desenvolvimento Rural, Programa de Apoio à Produção e Exportação de Frutas, Hortaliças, Flores e Plantas Ornamentais. Brasília: EMBRAPA-SPI, 1993. 35P. (Série publicações técnicas FRUPEX; 1).

[6] FERREIRA, D. F. Programa Sisvar.exe. Sistema de Análise de variância. Versão 4.3 (Build 45), (1999 - 2003).

[7] GORDON, J. MC DOUGALL, IAN M. MORRISON, DEREK STWARR AND JOHN R HILLMAN. Plant Cell Walls as Dietary Fiber: Range, Structure, Processing and Function. Journal Science Food Agricultural. Great Britain v. 70, p. 133-150, 1996.

[8] HENDRICKSON, R.; J. W. KESTERSON. By products of florida citrus: Composition, Techonology and Utilization. Fla. Agr. Exp. Sta. Bull p. 698, 1965.

[9] HULME, A.C. The biochemistry of fruits and their products. London, Academic Press, 1971, v. 2, 788 p.

[10] KLAVONS, J. A., BENNETT, R. D. \& VANNIER, S.D. Physical and chemical nature of pectin associated with commercial orange juice cloud. Journal of Food Science, Chicago, v. 59, n. 2, p. 399-401, 1994.

[11] LÁSZLÓ, F. Óleos Essenciais Cítricos - seu poder terapêutico na aromaterapia. Disponível em: < http://www. jardimdeflores.com.br/sinergia/S13oleoscitricos.htm $>$. Acesso em: 05 jan. 2006.

[12] MARKS, J. A guide to the vitamins (Their role in health and disease). Pantothenic Acid. England: Lancaster p. 125-130, 1975.
[13] MC CREADY, P. M.; Mc COMB, E. A. Extration and determination of total pectic material. Analytical chemistry, Washington, v. 24, n. 12, p. 1586-1588, 1952.

[14] NASCENTE, A. S. Aproveitamento de subprodutos de frutas. Embrapa. Rondônia. Disponível em <http//:www. cpafro.embrapa.br/embrapa/Artigos/aprov_subprod. htm $>$. Acesso em 13 setembro de 2006.

[15] NEVES, N. M. S. Nutrição e doença cardiovascular, Rio de Janeiro: Ed. Guanabara Koogan S.A. 1997, 114 p.

[16] STERN, M.D.; ZIEMER, C. J. Consider value, cost when selecting nonforage fiber. Feedstuffs, Minnetonka, v. 11, p.14, jan 1993.

[17] STROHECKER, R.; HENNING, H. M. Analisis de vitaminas, modos comprobados. Madri: Paz Montalvo, $1967.428 \mathrm{p}$.

[18] TODA FRUTA. Informações econômicas sobre o limão. Disponível em <http://www.todafruta.com.br/>. Acesso em 09 janeiro de 2006.

[19] TING; ATTAWAY, J. A. Citrus fruit. In: HULME, A.C. The biochemistry of fruit and their products. v. 2, London Academic Press, 1971. p. 107-171.

[20] VAN DE KAMER, S. B.; VAN GINKEL, L. Rapid determination of crude fiber in cereals. Cereal Chemistry, Saint Paul, v. 19, n. 4, p.239-251, July./Aug. 1952.

[21] VAN SOEST, P. J.; J. B. ROBERTSON; B. A. LEWIS. Methods for dietary fiber, neutral detergent fiber, and nonstarch polysaccharides in relation to animal nutrition. Journal of Dairy Science, v. 74 n. 10, p. 3583-3596, 1991.

[22] VELLOSO, L.; Uso da polpa cítrica na alimentação animal. Comunicação Científica. Faculdade de Medicina Veterinária e Zootecnia. São Paulo. n. 9, v. 2, p. 163-180, 1985.

[23] VILAS BOAS et al. Manejo de Resíduos da Agroindústria. Lavras: UFLA/FAEPE, 2001, 110 p.

\section{6 - AGRADECIMENTOS}

Ao Conselho Nacional de Desenvolvimento Científico e Tecnológico (CNPq) pela concessão da bolsa de estudos e à Tina e à Sandra, funcionárias do Departamento de Ciência dos Alimentos da UFLA, pela ajuda na execução das análises. 